\title{
The Inhibition Action of Viscum Album Extract on the Corrosion of Carbon Steel in Hydrochloric Acid Solution
}

\author{
Osama A. Elgyar ${ }^{1}$, Abdelfattah M. Ouf ${ }^{1}$, Ahmed El-Hossiany 1,2 ${ }^{\mathbb{D}}$, Abd El-Aziz S. Fouda 1,*(D) \\ 1 Department of Chemistry, Faculty of Science, El-Mansoura University, Egypt; asfouda@mans.edu.eg (A.S.F.); \\ 2 Delta for Fertilizers and Chemical Industries, Talkha, Daqahlia, 1179 Egypt \\ * Correspondence: asfouda@mans.edu.eg (A.S.F.);
}

Received: 2.02.20211; Revised: 1.03.2021; Accepted: 3.03.2021; Published: 10.03.2021

\begin{abstract}
Corrosion rate of carbon steel (CS) in $1 \mathrm{M} \mathrm{HCl}$ was examined in the absence and presence of Viscum album plant extract as a corrosion inhibitor using weight loss, polarization, and impedance techniques. The effect of temperature and extract dose was studied using a weight loss test. The outcome data gained displayed that Viscum album extract plays as an inhibitor for $\mathrm{CS}$ in $\mathrm{HCl}$ and reduces the corrosion rate. The higher inhibition efficacy reached $96.3 \%$ for Viscum album at greater inhibitor doses $(300 \mathrm{ppm})$ and temperature. Polarization data revealed that this extract acts as a mixed kind inhibitor. The surface analysis of CS was checked by different methods, which showed the formation of extract film on the CS surface. The adsorption of Viscum album plant extract was found to obey the Temkin model, and the data of adsorption free energy was more negative than $-40 \mathrm{~kJ} / \mathrm{mol}$, which means that the adsorption is chemical.
\end{abstract}

Keywords: corrosion inhibition; Viscum album extract; HCl; Temkin isotherm; adsorption.

(C) 2021 by the authors. This article is an open-access article distributed under the terms and conditions of the Creative Commons Attribution (CC BY) license (https://creativecommons.org/licenses/by/4.0/).

\section{Introduction}

Carbon steel is one of the iron alloys that is commonly used in the manufacture of consumer goods because it has best at low-temperature flexibility, hydrogen-induced cracking, and aqueous solutions of acids are commonly used in the pickling, acid washing of descaling, boilers, and well-acidifying oil industries [1,2]. The chief problem with CS functions is its reasonably small resistance to corrosion in an acidic environment, particularly hydrochloric and sulphuric acid solutions. Plant extracts are shown to be excellent corrosion inhibitors because they are green, simple to obtain, environmentally friendly, and low cost-effective [3]. The green corrosion plant extracts mainly contain the requiring elements (such as $\mathrm{O}, \mathrm{N}$, and S) that help molecules be adsorbed on the metals or alloys' surface to form a film that protects the surface from getting corroded [4]. Table 1 employs the use of some plant extracts as inhibitors to lower the corrosion of steel in several typical industrial solutions, which was performed by several authors [5-8]:

Table 1. List of plant sources utilized for dissolution inhibition studies.

\begin{tabular}{l|c|c|c}
\multicolumn{1}{c|}{ Extract } & Metal/Medium & IE\% & Ref. \\
\hline Gloriosa superba seeds extract & Carbon steel / $\mathrm{H}_{2} \mathrm{SO}_{4}$ & 91 & 5 \\
\hline Mimosa pudica leaves & Mild steel / $\mathrm{HCl}$ & 77 & 6 \\
\hline Peach Pomace Extract & Carbon steel / NaCl & $18-90$ & 7 \\
\hline Cola acuminata extract & Carbon steel / $\mathrm{HCl}$ & 74 & 8
\end{tabular}


The current paper aims to understand the resistance of corrosion in a solution of $1 \mathrm{M}$ $\mathrm{HCl}$ using Viscum album extract that is derived from a plant origin. Therefore, this extract's choice as corrosion was made in acidic media based on its non-toxicity, cheap and high solubility. Investigation of corrosion inhibition action of Viscum album extract on CS in $1 \mathrm{M}$ $\mathrm{HCl}$ solutions was made by several techniques.

\section{Experimental Techniques}

\subsection{Materials and reagents.}

The acid corrosive environment $(1 \mathrm{M} \mathrm{HCl})$ was prepared by diluting a reagent of analytical grade $\mathrm{HCl} 37 \%$ with bi-distilled water. The composition of the applied CS as weight $\%$ is: $\mathrm{C}(0.2 \%),(\mathrm{Mn}(0.35 \%), \mathrm{P}(0.024 \%), \mathrm{Si}(0.003 \%)$, and balance Fe. The CS sheet of thickness $0.2 \mathrm{~cm}$ was mechanically press-cut into $2 \times 2 \mathrm{~cm}$ coupons for weight loss tests. The samples were abraded with varying degrees of emery papers from 400 and 2000 grades, cleaned and washed using acetone, rinsed with bi-distilled water, and dried with filter paper. The coupons were then ready to use in the corrosion studies. Proper doses of the acid were prepared to utilize bi-distilled water. Viscum album extract doses vary between (50-300 ppm) in $1.0 \mathrm{M}$ $\mathrm{HCl}$.

\subsection{Viscum album procedure.}

The got dried plant was ground into little pieces of 5 to $20 \mathrm{~mm}$ with a grinder processor, and dissolution happened using bi-distilled water. At that point, $0.1 \mathrm{~kg}$ of the got dried plant was adding to $250 \mathrm{ml}$ of bi-distilled water at $80^{\circ} \mathrm{C}$ for thirty minutes, at that point store for 24 $\mathrm{h}$ and filter by a filter paper then diluted to $1 \mathrm{~L}$ by bi-distilled water, lastly kept in a cooling framework in a flask closed with a plastic cover. A large quantity of highly polar compounds, such as "amino acids, monosaccharides, sugar acids, sugar alcohols, peptides, organic acids, nucleobases, and nucleosides" were found in the aqueous extract of the Viscum album [9,10], as shown in Figure1 with their ratios:
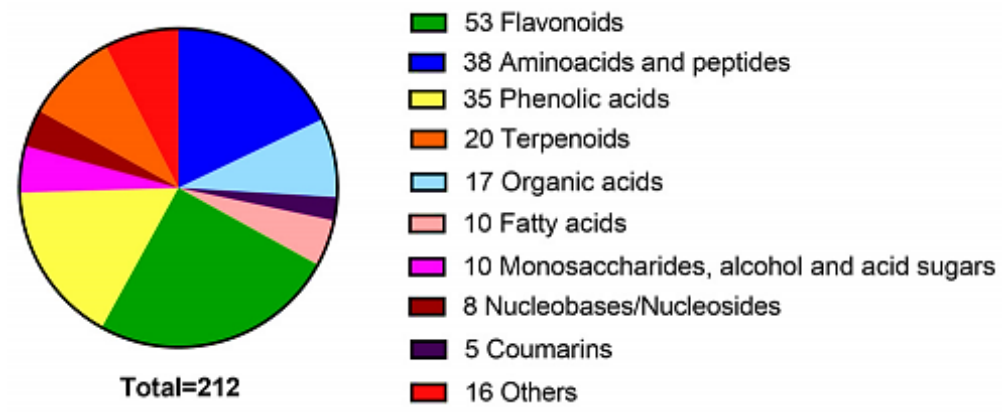

Figure 1. Chemical composition of Viscum album extract

\subsection{Mass loss $(M L)$ tests.}

Carbon steel samples with dimensions $2 \times 2 \times 0.2 \mathrm{~cm}$ were prepared as previous and weighed accurately, then suspended in a solution of $100 \mathrm{ml}$ of the acid corrosive environment without and with $(50,100,150,200,250$, and $300 \mathrm{ppm})$ of Viscum album extract for at altered dipping times ( 3 hours). The average ML at a definite time for these samples were determined after recording the results in each temperature, the surface coverage, $\theta$, and inhibition efficacy, \%IE, had been measured utilizing the following equation:

$$
\% \mathrm{IE}=\theta \times 100=\left(\mathrm{W}_{\text {inh }}-\mathrm{W}_{\text {free }}\right) / \mathrm{W}_{\text {free }} \times 100
$$


where $\mathrm{W}_{\text {inh }}$ and $\mathrm{W}_{\text {free }}$ are the MLs of CS specimens in the existence and absence of Viscum album, correspondingly [11-13].

\subsection{Electrochemical tests.}

All electrochemical techniques were utilized through a cell involving three classic electrodes, the working electrode that is utilized CS for study. The second electrode is the reference electrode (saturated calomel electrode, SCE), and the third electrode is the platinum foil. Before each electrochemical procedure, the CS electrode was left $30 \mathrm{~min}$ in the solution to give a chance for the open circuit potential (OCP) to attain (a steady-state). Each experiment was achieved on a newly abraded electrode utilizing a freshly prepared electrolyte.

PP acquired by altering the electrode potential from -500 to $500 \mathrm{mV}$ vs. (OCP), with a scan rate of $1 \mathrm{mVs}^{-1}$.

EIS tests have been performed on the experiment by utilizing AC signals ranging from $(100 \mathrm{kHz}$ to $0.1 \mathrm{~Hz})$, with an amplitude of peaks $10 \mathrm{mV}$ at OCP [14, 15]. All the results of impedance were compatible with the appropriate equivalent circuit using the Gamry Echem program,

Electrochemical techniques were achieved by utilizing Potentiostat/ Galvanostat (PCI4G750) with software DC105, EIS300 for PP and EIS tests, respectively, linked to a computer for data documented and saved.

\subsection{Morphology of the surface.}

2.5.1 Atomic force microscopy (AFM) analysis.

AFM is an adapted test provide data on the surface examination of CS sample with measured linear purity. Measured knowledge is implemented and valued through persecution From the SPM management computer code [16].

\subsubsection{Attenuated total reflection infrared (ATR-IR).}

FT-IR spectra were registered in a spectral range 4000 to $500 \mathrm{~cm}^{-1}$ with the technique of Attenuated Total Reflectance (ATR) using FTIR-Spectrometer iS 10 (Thermo Fisher Scientific, USA). FT-IR spectrum is an effective way to compare between the inhibitor and corrosion products after inhibitor adsorption. The FT-IR peak values were recorded for Viscum album extract and for CS after immersion for 24 hours in the corrosive acid medium with 300 ppm of Viscum album extract [17].

\subsubsection{X-ray spectroscopy (XPS) examination.}

In this study, the morphology of CS metal samples was tested before and after being immersed in a solution of $1 \mathrm{M}$ hydrochloric acid in the presence and absence of Viscum album extract $(300 \mathrm{ppm})$ for three hours using electronic X-ray spectroscopy (XPS) and measurements were made using a device ESCALAB 250Xi, Thermo-Scientific, USA. In this technique, CS coupons were handled the same way as previous treatment coupons were treated for an ML experience.

\section{Results and Discussion}

\subsection{ML method.}


The corrosion method of CS in an aqueous solution is described by the amount to which it dissolved in the solution [18]. The ML is a conventional test to calculate the rate of corrosion. These tests clearly estimate the Viscum album extract's quality and the surface protecting capability of the Viscum album at maximum temperatures. This method is proved to be the most accurate test to determine the efficacy of the inhibitor $(\% \mathrm{IE})$ and corrosion rate $\left(\mathrm{k}_{\text {corr }}\right)$ (Figure 2 and Table 2).

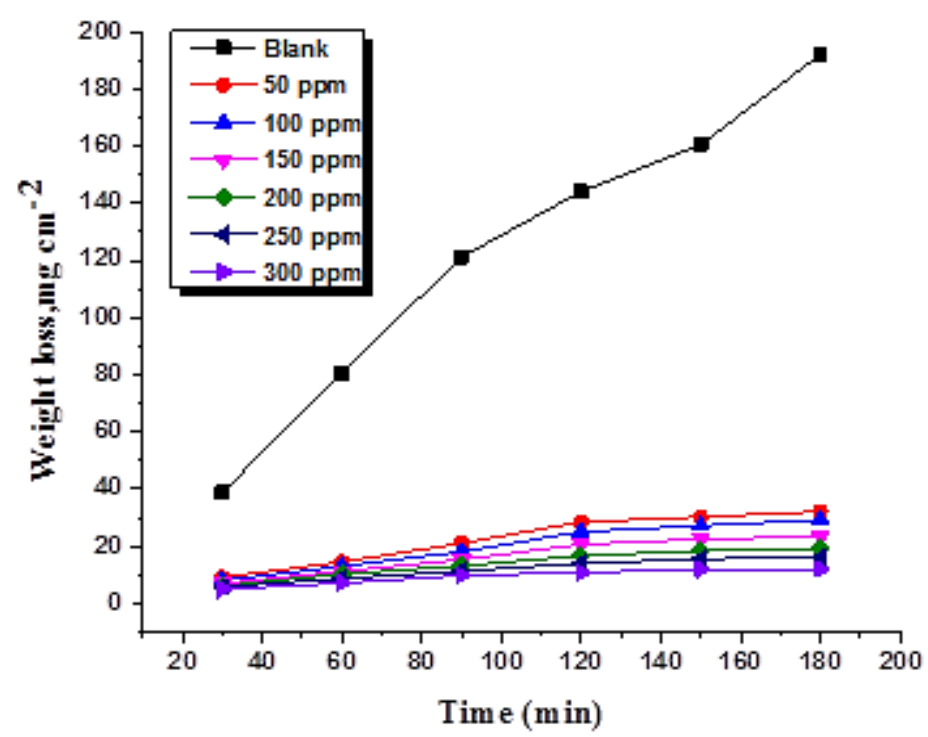

Figure 2. Time-ML curves for the dissolution of CS in $1 \mathrm{M} \mathrm{HCl}$ in the attendance and absence of altered doses of Viscum album extract at $25^{\circ} \mathrm{C}$.

Table 2. Variation of $\mathrm{k}_{\mathrm{corr}}, \Theta$ and $\% \mathrm{IE}$ for altered doses of Viscum album extract at $2{ }^{\circ} \mathrm{C}$.

\begin{tabular}{c|c|c|c}
$\begin{array}{c}\text { Conc., } \\
\mathbf{p p m}\end{array}$ & $\begin{array}{c}\mathbf{k}_{\mathbf{c o r r}}, \\
\mathbf{m g ~ c m}^{-\mathbf{2}} \mathbf{~ m i n}^{\mathbf{- 1}}\end{array}$ & $\boldsymbol{\Theta}$ & $\mathbf{\% I E}$ \\
\hline Blank & 1.201 & ---- & ---- \\
\hline 50 & $0 . .238$ & 0.802 & 80.2 \\
\hline 100 & 0.209 & 0.826 & 82.6 \\
\hline 150 & 0.172 & 0.857 & 85.7 \\
\hline 200 & 0.139 & 0.884 & 88.4 \\
\hline 250 & 0.116 & 0.903 & 90.3 \\
\hline 300 & 0.09 & 0.925 & 92.5
\end{tabular}

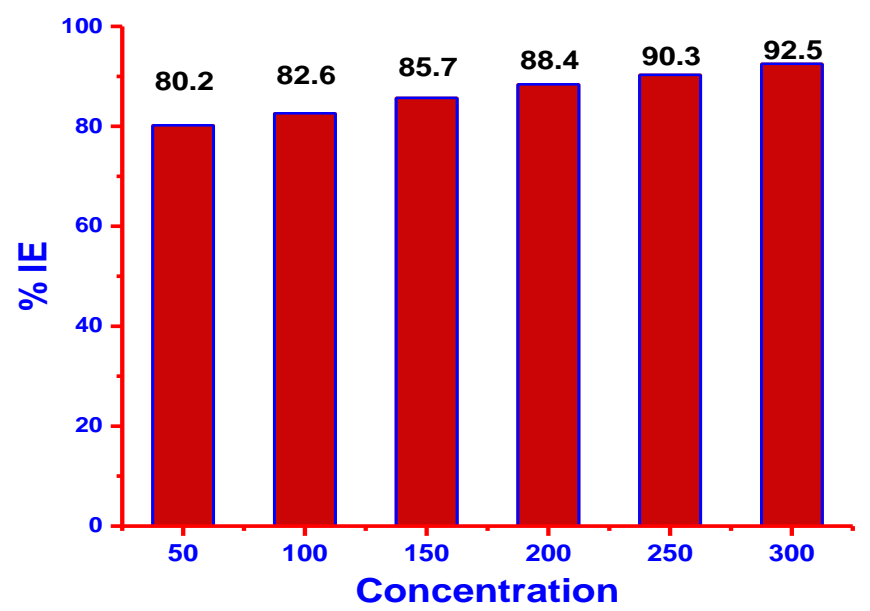

Figure 3. Variation of $\% \mathrm{IE}$ with $\mathrm{CS}$ doses in $1 \mathrm{M} \mathrm{HCl}$ for Viscum album extract at $25^{\circ} \mathrm{C}$. 
The ML test is usually preferred because the quantity calculated was directly proportional to the amount of dissolution. The difference of ML with time in uninhibited and inhibited aerated acid indicates the absence of insoluble surface films through corrosion where the Viscum album extract is first adsorbed on the CS surface, therefore, decreased the corrosion rate and increased \%IE by blocking the active centers on CS surface Figure 3.

\subsection{Effect of temperature.}

The \%IE of CS corrosion in the attendance of altered doses of the Viscum album extract at various temperatures $\left(25-45^{\circ} \mathrm{C}\right)$ was achieved by Eq. (1). "It was established that the ML improves with raising the temperature from $25^{\circ} \mathrm{C}$ till it reached $45^{\circ} \mathrm{C}$. This can be described as conferring to the rule that higher temperatures might give rise to a protective layer formed on CS surface. They are suggesting that the Viscum album extract species are adsorbed on the CS /solution interface chemically and form a coated film on the CS surface, which hindrance the action of the corrosion". A rising in the Viscum album extract efficacy with increment temperature was detected, demonstrating that Viscum album extract adsorbed on CS surface at these conditions chemically and reveals that the corrosion rate (kcorr) of $\mathrm{CS}$ in $\mathrm{HCl}$ in the presence of Viscum album extract decreases as temperatures increased as shown in Table 3.

Table 3. Variation ML $\left(\mathrm{k}_{\mathrm{corr}},\left(\mathrm{mg} \mathrm{cm} \mathrm{min}^{-1}\right)\right.$ and $\theta$ for the dissolution of $\mathrm{CS}$ in $1 \mathrm{M} \mathrm{HCl}$ without and the existence of altered doses of Viscum album extract at different temperatures.

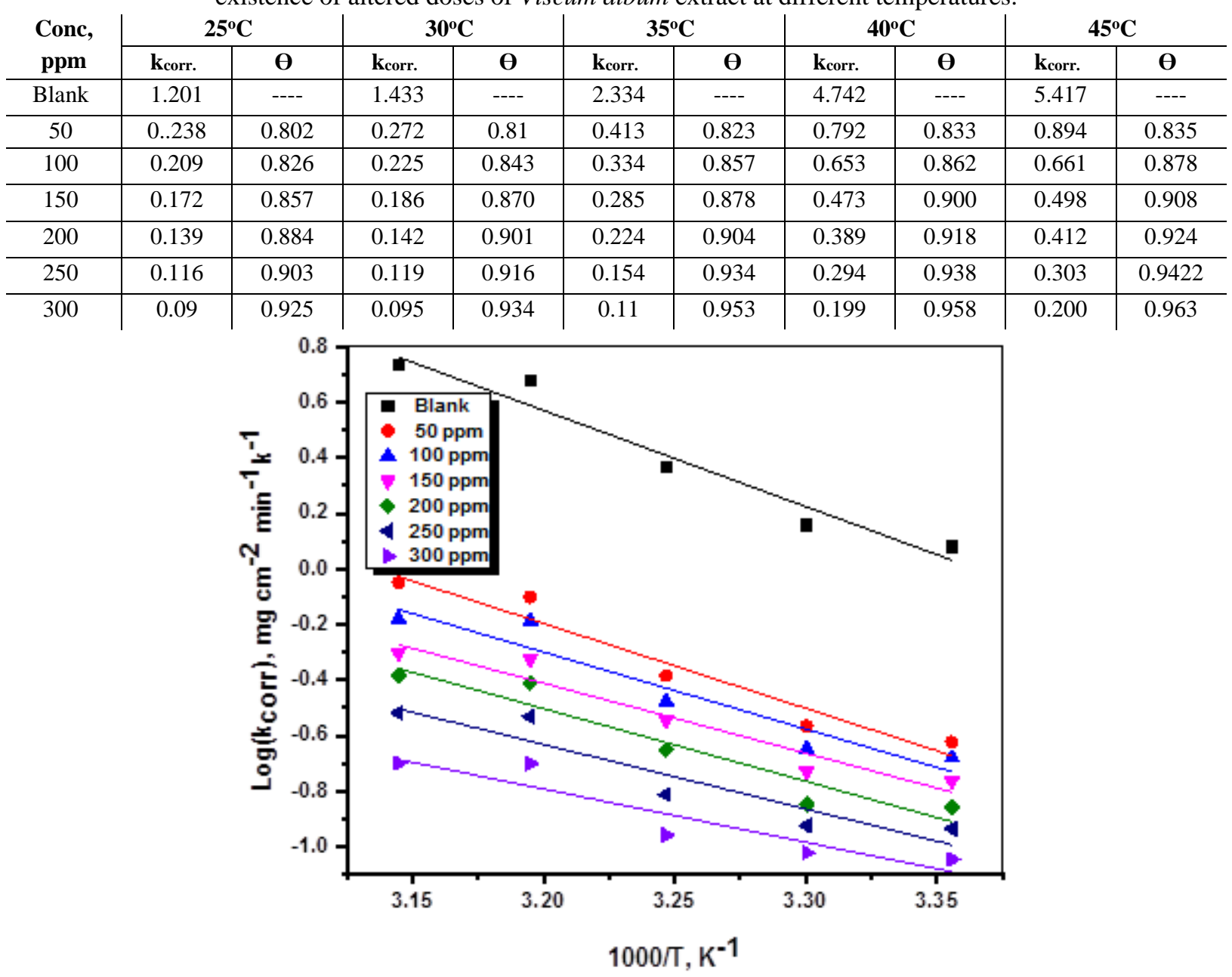

Figure 4. $\log \mathrm{k}_{\text {corr }}$ of CS vs. 1000/T in the absence and attendance of altered doses of Viscum album extract in $1 \mathrm{M} \mathrm{HCl}$. 


\subsection{Thermodynamic corrosion parameters.}

The activation energy $\left(\mathrm{Ea}^{*}\right)$, the enthalpy $\left(\Delta \mathrm{H}^{*}\right)$ and entropy of activation $\left(\Delta \mathrm{S}^{*}\right)$ for the dissolution of CS in hydrochloric acid solution in the attendance and absence of altered doses of Viscum album extract at $25-45^{\circ} \mathrm{C}$ were measured from Arrhenius Eq. below [19]:

$$
\left(\mathrm{k}_{\mathrm{corr}}\right)=\mathrm{A} \exp \left(-\mathrm{E}_{\mathrm{a}}{ }^{*} / \mathrm{RT}\right)
$$

where "A is the Arrhenius pre-exponential factor, and $\mathrm{h}$ is the Planck's constant". A drawn of $1 / \mathrm{T}$ vs. $\log \mathrm{k}$ corr displayed in Fig. (4). $\Delta \mathrm{H}^{*}$ and $\Delta \mathrm{S}^{*}$ for the transitional complex were acquired by relating the transition state [20].

$$
\left(\mathrm{k}_{\text {corr }}\right)=\mathrm{RT} / \mathrm{Nh} \exp \left(\Delta \mathrm{S}^{*} / \mathrm{R}\right) \exp \left(-\Delta \mathrm{H}^{*} / \mathrm{RT}\right)
$$

A draw of $\log \left(\mathrm{k}_{\text {corr }} / \mathrm{T}\right)$ against $1 / \mathrm{T}$ would give straight lines from which the data of $\Delta \mathrm{H}^{*}$ and $\Delta \mathrm{S}^{*}$ were intended, correspondingly as displayed in Figure 5.

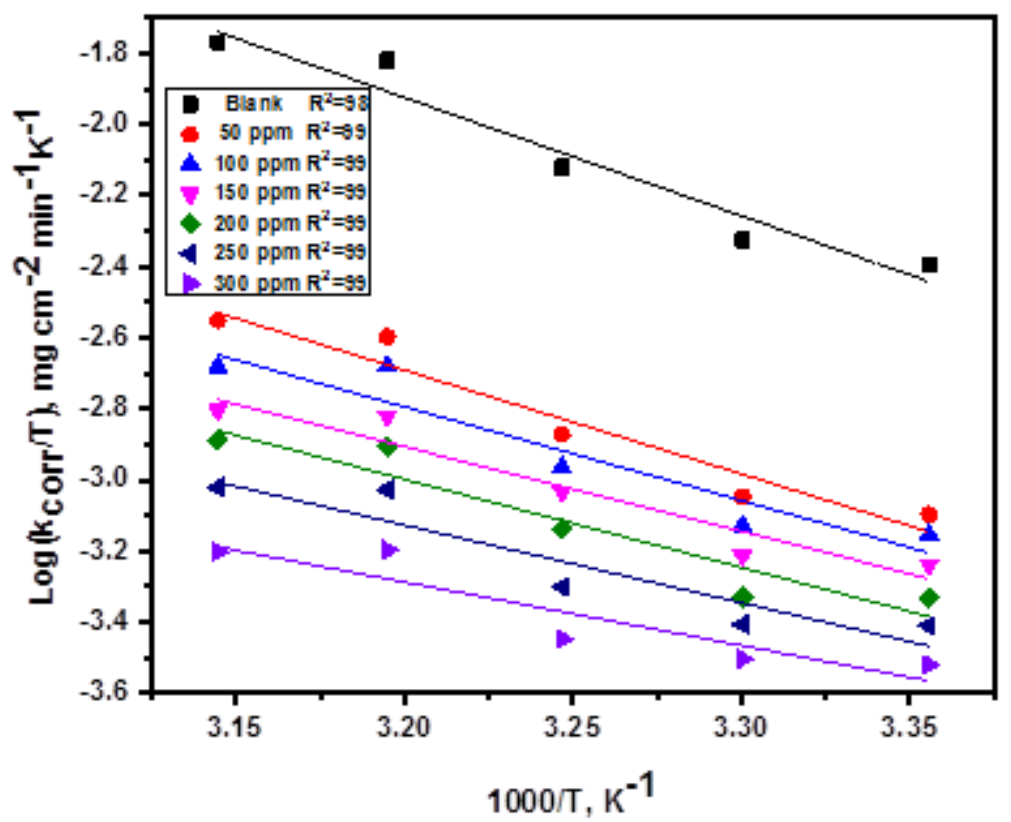

Figure 5. $\log \mathrm{k}_{\text {corr }}$ of CS vs. 1000/T in the absence and attendance of altered doses of Viscum album extract in $1 \mathrm{M} \mathrm{HCl}$.

\begin{tabular}{|c|c|c|c|c|}
\hline Compound & $\begin{array}{c}\text { Conc. } \\
\text { ppm }\end{array}$ & $\begin{array}{c}\mathrm{E}_{\mathrm{a}} * \\
\mathbf{k J} \mathrm{mol}^{-1}\end{array}$ & $\begin{array}{c}\Delta \mathbf{H}^{*} \\
\mathbf{k J} \mathrm{mol}^{-1}\end{array}$ & $\begin{array}{c}-\Delta \mathbf{S}^{*} \\
\mathbf{J} \mathbf{m o l}^{-1} \mathbf{K}^{-1}\end{array}$ \\
\hline Blank & $1 \mathrm{M} \mathrm{HCl}$ & 66.24 & 63.61 & 30.48 \\
\hline \multirow[t]{6}{*}{ Viscum album } & 50 & 58.47 & 55.90 & 70.12 \\
\hline & 100 & 53.01 & 50.43 & 89.55 \\
\hline & 150 & 48.19 & 45.61 & 107.13 \\
\hline & 200 & 49.97 & 47.48 & 102.89 \\
\hline & 250 & 44.40 & 41.82 & 123.50 \\
\hline & 300 & 36.70 & 34.08 & 151.13 \\
\hline
\end{tabular}

Table 4. Kinetic parameters of Arrhenius and transition state equations.

As displayed in Table $4, \mathrm{E}_{\mathrm{a}}{ }^{*}$ has lesser values in the solution containing the Viscum album extract than that of the Viscum album's absence. "The lowered in the $\mathrm{E}_{\mathrm{a}}{ }^{*}$ on the protected solutions lead to the higher IE of Viscum album extract. The decrease data of the $\mathrm{E}_{\mathrm{a}}{ }^{*}$ refers to the adsorption of Viscum album extract on the CS surface chemically and creating a stable metal-inhibitor complex. $\Delta \mathrm{H}^{*}$ have a positive symbol designates endothermic procedure and designates strong adsorption of Viscum album extract on the CS" and confirm the chemical adsorption of the extract on CS surface. $\Delta S^{*}$ have negative data that leads to the activated 
complex in the rate-determining stage. It demonstrates coagulation not an isolated, that designates the reduction in disorder [21].

\subsection{Adsorption isotherm.}

The analysis of adsorption isotherm offers some supporting details on the corrosion inhibition process. After examination of all adsorption isotherms, we conclude that the best isotherm that fits the results is Temkin isotherm, so:

$$
\Theta=2.303 / \mathrm{a} \log \mathrm{K}_{\mathrm{ads}}+2.303 / \mathrm{a} \log \mathrm{C}
$$

where "C is the dose (M), $\mathrm{K}_{\mathrm{ads}}$ is the adsorption equilibrium constant, (a) is a molecular interaction parameter". A graph of $\theta$ against $\log \mathrm{C}$ gives straight lines as appeared in Fig.6. Thermodynamic parameters of adsorption were calculated and tabulated in Table 5. The essential parameters were calculated as $\left(\Delta \mathrm{G}^{\circ}\right.$ ads $),\left(\Delta \mathrm{H}^{\circ}\right.$ ads $)$ and $\left(\Delta \mathrm{S}^{\circ}\right.$ ads $)$ after assessment of $\mathrm{K}_{\text {ads }}$. at various temperatures Fig.7. The change in free energy can be calculated from Eq. (5):

$$
\log \mathrm{K}_{\mathrm{ads}}=1 / 55.5 \exp \left(\Delta \mathrm{G}_{\text {ads }}^{\mathrm{o}} / 2.303 \mathrm{RT}\right)
$$

where 55.5 is to the water dose in $(\mathrm{mol} / \mathrm{L})$ at the interface of solution/metal. The counted values of $\mathrm{K}_{\text {ads }}$ and $\Delta \mathrm{G}^{\mathrm{o}}$ ads were tabulated in Table 5. The negative values of $\Delta \mathrm{G}^{\mathrm{o}}$ ads point out that the adsorption process of the extract on the CS surface is spontaneous. The higher values for $\Delta \mathrm{G}^{\mathrm{o}}$ ads lie between 45.7 to $49.9 \mathrm{~kJ} / \mathrm{mol}$ for Viscum album extract exhibiting chemisorption [22]. The enthalpy of adsorption $\left(\Delta \mathrm{H}^{\mathrm{o}}\right.$ ads $)$ was computed utilizing the following Vant Hoff Eq.:

$\log \mathrm{K}_{\mathrm{ads}}=-\Delta \mathrm{H}^{\mathrm{o}}{ }_{\mathrm{ads}} / 2.303 \mathrm{RT}+\mathrm{constant}$

Plotting $\log \mathrm{K}_{\text {ads }}$ versus $1 / \mathrm{T}$ gives a straight line, as shown in Fig. 7. The entropy of adsorption $\left(\Delta \mathrm{S}^{\mathrm{o}}{ }_{\text {ads }}\right)$ can be calculated from the following Eq.:

$$
\Delta \mathrm{S}_{\text {ads }}^{\mathrm{o}}=\left(\Delta \mathrm{H}^{\mathrm{o}} \text { ads }-\Delta \mathrm{G}^{\mathrm{o}} \text { ads }\right) / \mathrm{T}
$$

The calculated $\Delta \mathrm{H}^{\mathrm{o}}$ ads and $\Delta \mathrm{S}^{\circ}$ ads values are listed in Table $5 . \Delta \mathrm{H}_{\text {ads }}^{\circ}$ was $18.3 \mathrm{~kJ} \mathrm{~mol}^{-1}$ for Viscum album extract with a positive signal signifying endothermic reaction, which expected to be more chemisorption than physisorption. The calculated values of $\Delta \mathrm{S}^{\mathrm{o}}$ ads point out that an entropy decrease accompanied the process of adsorption.

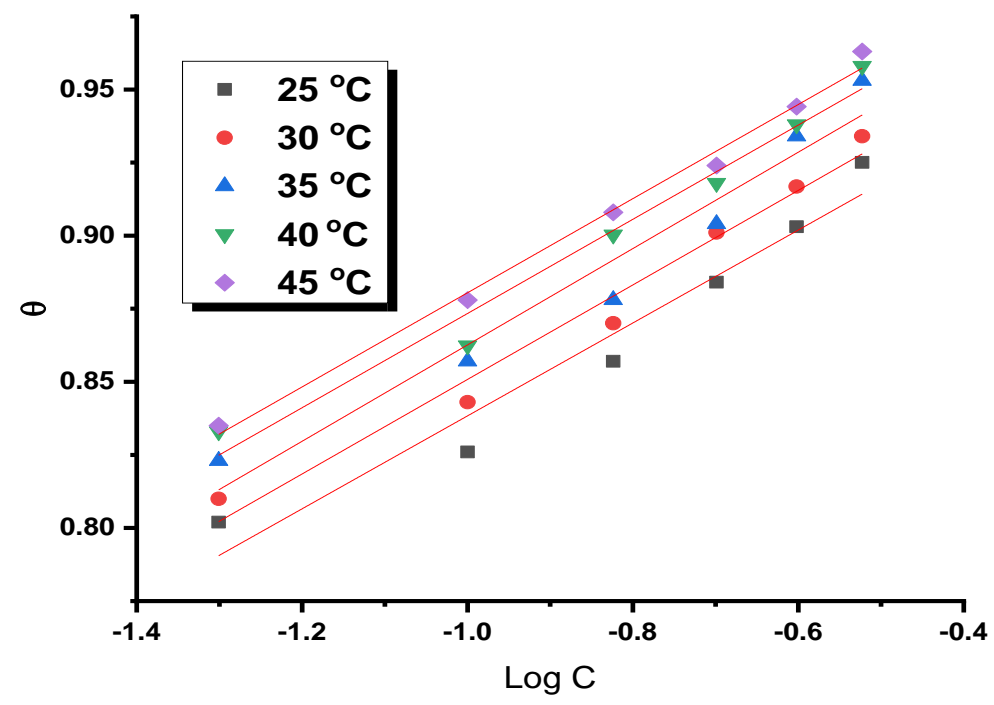

Figure 6. $\log \mathrm{C}$ of Viscum album extract with $\Theta$ Applied at altered temperatures in $1 \mathrm{M} \mathrm{HCl}$.

Table 5. Adsorption parameters for CS in the corrosive acid medium in the existence of Viscum album extract at

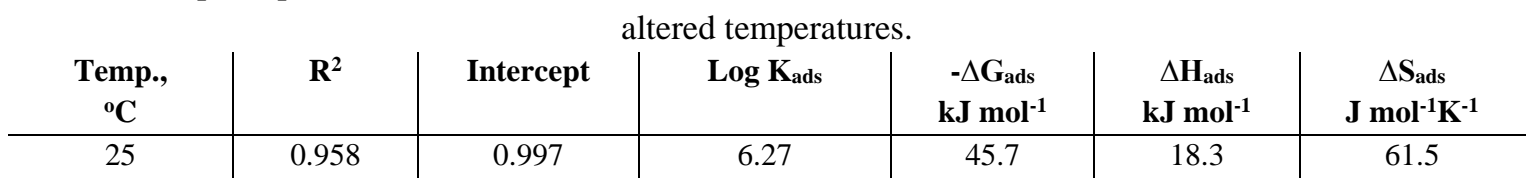




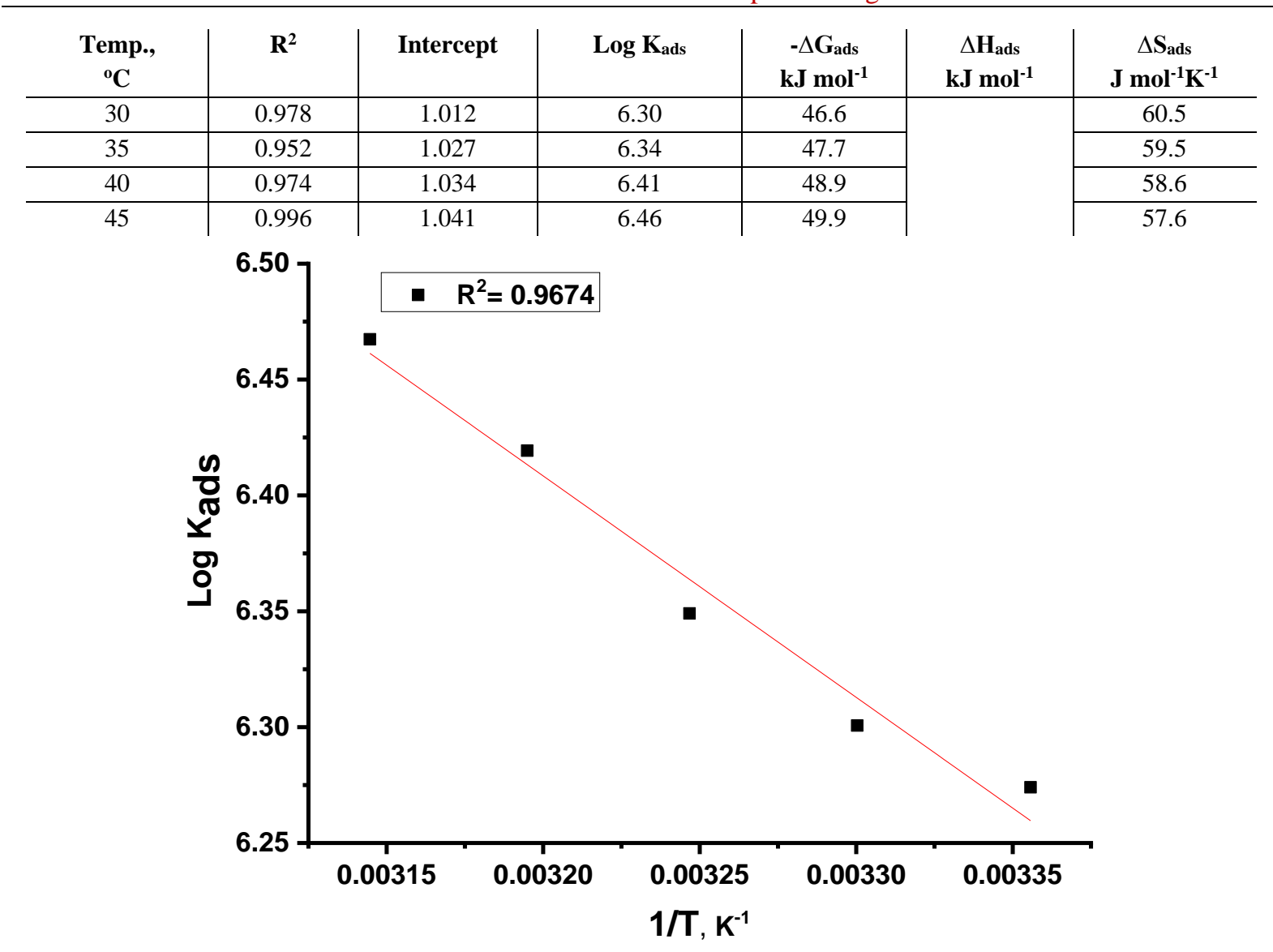

Figure 7. $\log \mathrm{K}_{\mathrm{ads}}$ vs. temperature $1 / \mathrm{T}$ (Van Hoff equation).

\subsection{Potentiodynamic polarization (PP)measurements.}

Anodic and cathodic diagrams from PP tests at $25^{\circ} \mathrm{C}$ for CS in the acid corrosive medium with and without altered doses of Viscum album extract were documented in Figure 8. "kinetic parameters as corrosion current ( $\mathrm{i}_{\text {corr }}$ ), corrosion potential ( $\left.\mathrm{E}_{\mathrm{corr}}\right)$, and Tafel slopes $\beta_{\mathrm{a}}$ and $\beta_{\mathrm{c}}$ were gotten from the obtained figure and are shown in Table 6 for CS in $1 \mathrm{M} \mathrm{HCl}$ corrosive environment. \% IE rises with increasing the doses of the Viscum album extract. Figure 8 demonstrates that the $i_{\text {corr. }}$ data reduced by adding the extract, which lowered the CS oxidation indicating that Viscum album extract is a good inhibitor for CS corrosion in the acidic environment [23]. The increase of the Viscum album extract dose affects the anodic and cathodic directions of the PP diagrams. The parallel lines of the Tafel lines after the addition of the Viscum album extract indicate no change in the mechanism". As seen from Table 6, the corrosion potential (Ecorr) value change after adding the Viscum album extract is less than 85 $\mathrm{mV}$, which proves a mixed-kind inhibitor [24-27]. \%IE and $\theta$ can be calculated from PP measurements as illustrated in Eq. (8):

$$
\% \mathrm{IE}=\theta \times 100=\left[1-\left(\mathrm{i}_{\text {corr }} / \mathrm{i}_{\text {corr }}^{\mathrm{o}}\right)\right] \times 100
$$

where $\mathrm{i}_{\text {corr }}$ and $\mathrm{i}^{\mathrm{o}}$ corr are the corrosion current with Viscum album extract and without it, correspondingly. 


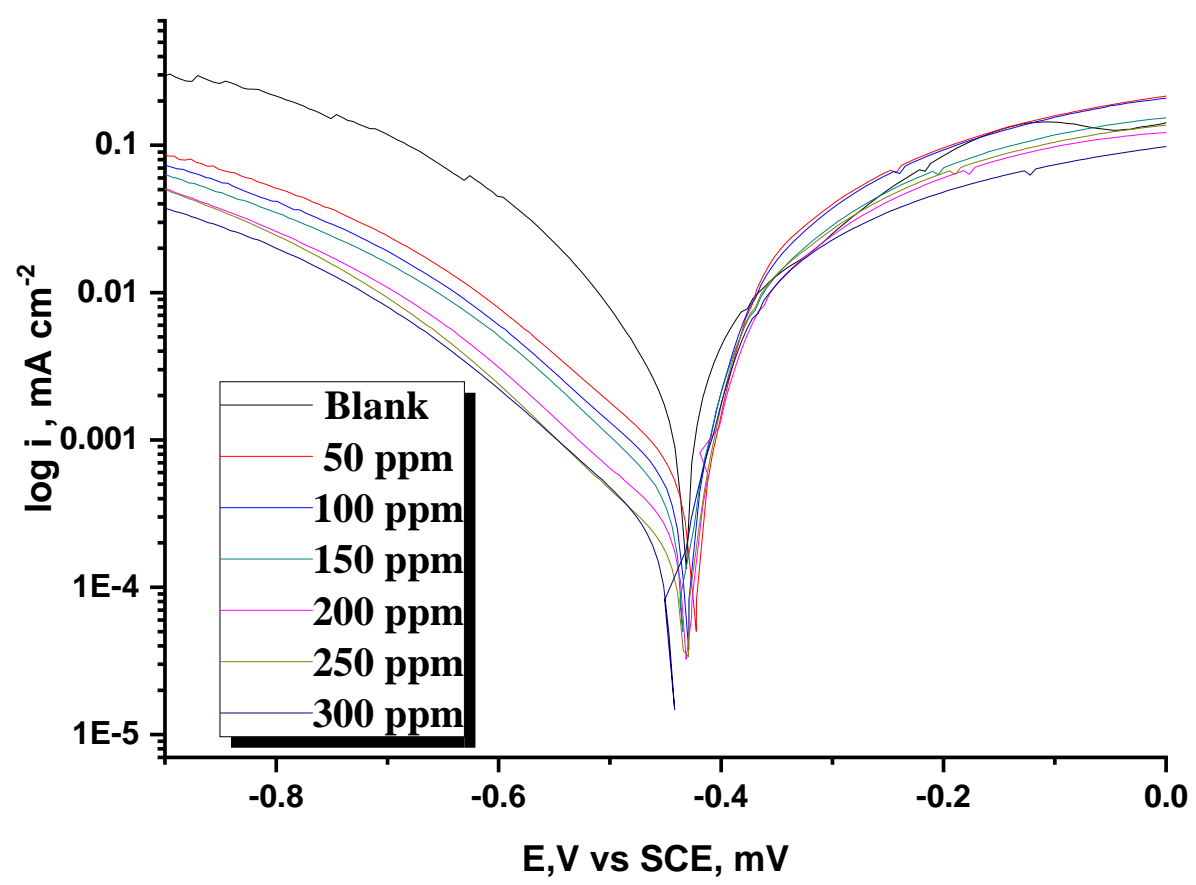

Figure 8. $\mathrm{PP}$ diagrams for $\mathrm{CS}$ in the $\mathrm{HCl}$ medium without and with altered doses of Viscum album extract at $25^{\circ} \mathrm{C}$.

Table 6. Electrochemical parameters were calculated by PP procedures for CS in $\mathrm{HCl}$ medium without and with altered doses of Viscum album extract at $25^{\circ} \mathrm{C}$.

\begin{tabular}{|c|c|c|c|c|c|c|c|}
\hline $\begin{array}{l}\text { Con. } \\
\text { ppm }\end{array}$ & $\begin{array}{c}\mathbf{i}_{\text {corr }} \\
\boldsymbol{\mu A} \mathbf{~ c m}^{-2}\end{array}$ & $\begin{array}{c}-E_{\text {corr, }} \\
\text { mV vs SCE }\end{array}$ & $\begin{array}{c}\beta_{\mathrm{a}} \\
\mathrm{mV} \operatorname{dec}^{-1}\end{array}$ & $\begin{array}{c}\beta_{c} \\
m V \operatorname{dec}^{-1}\end{array}$ & $\begin{array}{l}\text { C.R } \\
\text { mpy }\end{array}$ & $\boldsymbol{\theta}$ & $\%$ IE \\
\hline Blank & 995 & 433 & 120.0 & 151 & 390 & -- & -- \\
\hline 50 & 240 & 420 & 118 & 144 & 261 & 0.759 & 75.9 \\
\hline 100 & 210 & 419 & 119 & 141 & 255 & 0.789 & 78.9 \\
\hline 150 & 181 & 422 & 113 & 141 & 241 & 0.818 & 81.8 \\
\hline 200 & 144 & 412 & 111 & 147 & 231 & 0.855 & 85.5 \\
\hline 250 & 129 & 409 & 103 & 149 & 228 & 0.870 & 87.0 \\
\hline 300 & 99 & 400 & 100 & 148 & 122 & 0.900 & 90.0 \\
\hline
\end{tabular}

\subsection{EIS test.}

Nyquist and Bode diagrams obtained for CS dipping in $1.0 \mathrm{M} \mathrm{HCl}$ in the attendance and nonattendance of altered doses of Viscum album extract are displayed in Figs. 10 \&11. EIS parameters are given in Table 7. The equivalent circuit utilized to appropriate the EIS values was given in Figure 9. This circuit consists of stationary phase elements (CPE) rather than capacitors to give many heterogeneity types ideal for corrosion electrodes. Nyquist diagrams (Figure 10) showed that the semicircle diameter increases with the Viscum album extract dose rise. Subsequently, the charge transfer impedance is improved by the corrosion reaction. Nyquist plots' semi-circular shape proves that the process of charge transfer essentially controls the corrosion of CS [28]. The formed Viscum album film on CS surface minimizes the doublelayer capacitance $\left(\mathrm{C}_{\mathrm{dl}}\right)$ and increases the charge transfer resistance $\left(\mathrm{R}_{\mathrm{ct}}\right)$. The interfacial capacitance $\mathrm{C}_{\mathrm{dl}}$ data can be estimated from CPE parameter ( $\mathrm{Y}_{0}$ and $\mathrm{n}$ ) is defined in next Eq.:

$$
\mathrm{C}_{\mathrm{dl}}=\mathrm{Y}_{0}\left(\omega_{\max }\right)^{\mathrm{n}-1}
$$

where " $Y_{0}$ is the CPE magnitude, and $n$ is the variance CPE data of the: $-1<\mathrm{n}<1$ ". From Table 7, we observed a lower in the data of $\mathrm{C}_{\mathrm{dl}}$ with an addition in the dose of Viscum album extract, due to a lower in the local dielectric constant and/or rises in the thickness of the electrical double-layer [29]. \%IE and $\theta$ from EIS measurements were calculated as shown below: 


$$
\% \mathrm{IE}=\theta \times 100=\left[1-\left(\mathrm{R}_{\mathrm{ct}}^{\mathrm{o}} / \mathrm{R}_{\mathrm{ct}}\right)\right] \times 100
$$

where $\mathrm{R}_{\mathrm{ct}}$ and $\mathrm{R}_{\mathrm{ct}}^{\mathrm{o}}$ represent with Viscum album and without it, respectively

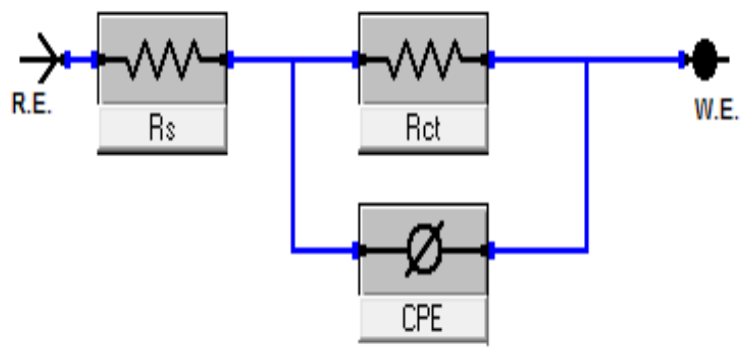

Figure 9. The equivalent circuit for fitting the EIS values.

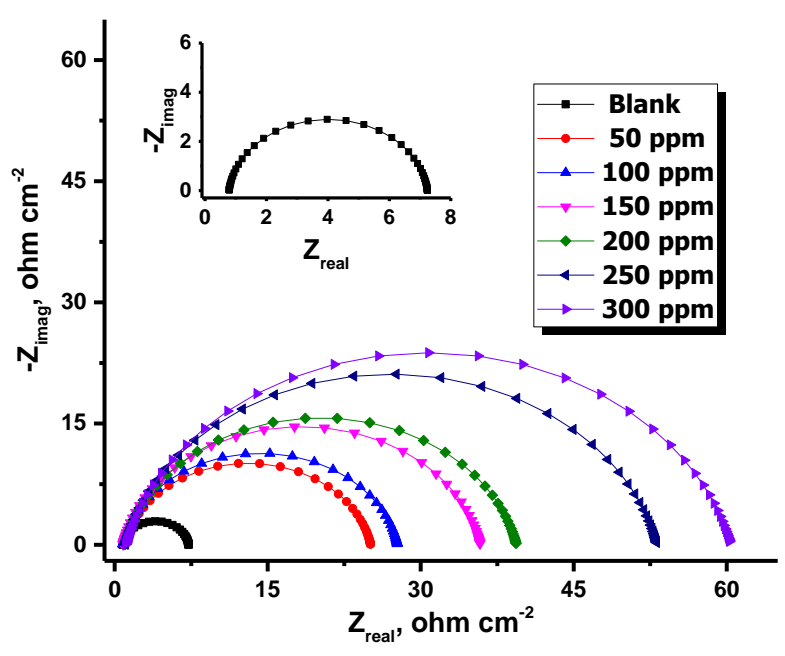

Figure 10. The Nyquist plots for CS dissolution in $1 \mathrm{M}$ $\mathrm{HCl}$ existence and nonexistence of altered doses of Viscum album extract at $25^{\circ} \mathrm{C}$

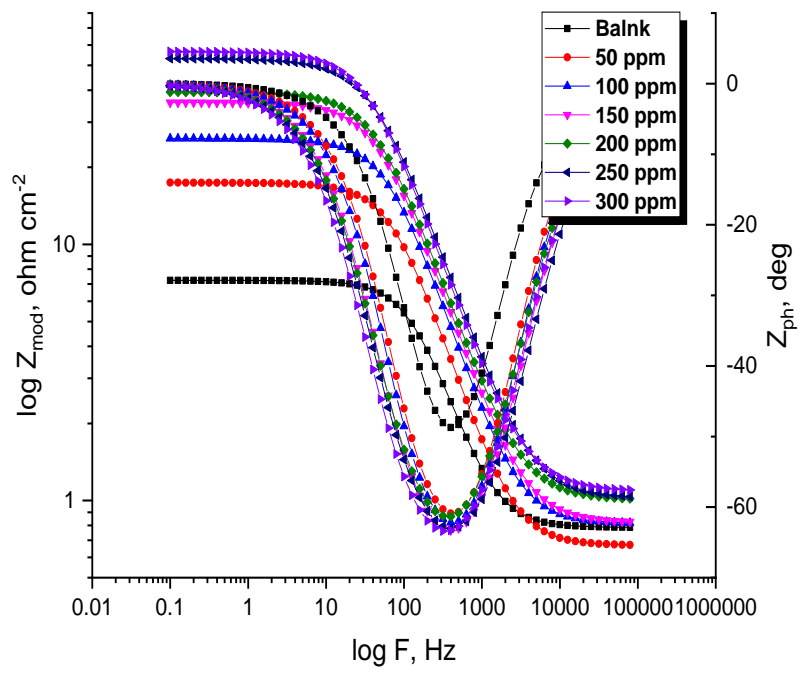

Figure 11. The Bode plots for CS dissolution in $1 \mathrm{M} \mathrm{HCl}$ attendance and absence altered dose of Viscum album at $25^{\circ} \mathrm{C}$

Table 7. EIS results for the dissolution of CS in $1.0 \mathrm{M} \mathrm{HCl}$ acid at altered doses of Viscum album extract at

\begin{tabular}{c|c|c|c|c|c|c}
$\begin{array}{c}\text { Conc., } \\
\mathbf{p p m}\end{array}$ & $\begin{array}{c}\mathbf{Y}_{\mathbf{0}, \mathbf{x}} \mathbf{1 0}^{\mathbf{6}} \\
\left(\mu \mathbf{\Omega}^{-1} \mathbf{s}^{\mathbf{n}} \mathbf{c m}^{-2}\right)\end{array}$ & $\mathbf{n}$ & $\begin{array}{c}\mathbf{R}_{\mathbf{c t}}, \\
\mathbf{\Omega ~ c m}^{\mathbf{2}}\end{array}$ & $\begin{array}{c}\mathbf{C}_{\mathbf{c l}}, \\
\boldsymbol{\mu} \mathbf{F} \mathbf{~ m}^{-2}\end{array}$ & $\boldsymbol{\Theta}$ & $\boldsymbol{\%} \mathbf{I E}$ \\
\hline $1 \mathrm{M} \mathrm{HCl}$ & 313 & 0.931 & 6 & 200 & ---- & ---- \\
\hline 50 & 183 & 0.910 & 24 & 107 & 0.750 & 75.0 \\
\hline 100 & 179 & 0.906 & 28 & 103 & 0.786 & 78.6 \\
\hline 150 & 163 & 0.885 & 39 & 85 & 0.846 & 84.6 \\
\hline 200 & 161 & 0.873 & 42 & 78 & 0.857 & 85.7 \\
\hline 250 & 155 & 0.866 & 58 & 74 & 0.897 & 89.7 \\
\hline 300 & 151 & 0.858 & 61 & 69 & 0.902 & 90.2
\end{tabular}

\subsection{Atomic force microscope (AFM) analysis.}

The CS morphology surface was analyzed using AFM experiments after dipping in $1 \mathrm{M} \mathrm{HCl}$ in attendance and absence of $300 \mathrm{ppm}$ of Viscum album extract for $24 \mathrm{~h}$ immersion, it can be gained regarding the roughness on the surface. "The mean roughness profile (Sa) values play an important role in identifying and reporting the efficacy of the extract under study [30]. Among the roughness, take a role in explaining the nature of the adsorbed film on the surface. Figure 12a gives the surface of the metal that was damaged by $\mathrm{HCl}$ (blank), which display high roughness $(\mathrm{Sa}=668) "$ and Figure $12 \mathrm{~b}$ shows the surface of the CS in the 
existence of 300 ppm of Viscum album, which is not affected by corrosion and becomes lower roughness $(\mathrm{Sa}=179)$.
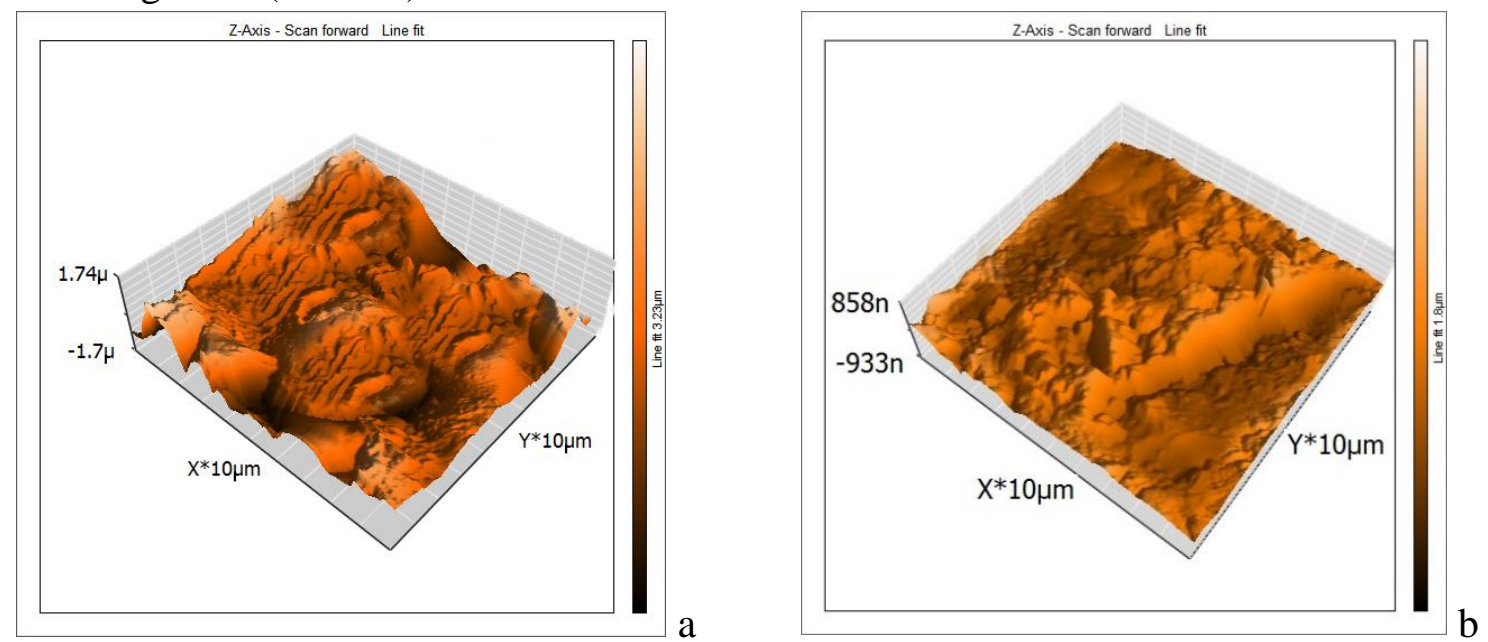

Figure 12. (a) An image was obtained for the immersion CS specimen in $1 \mathrm{M} \mathrm{HCl}$ without Viscum album extract; (b) referred to CS specimen after immersion of $1 \mathrm{M} \mathrm{HCl}+300 \mathrm{ppm}$ Viscum album extract for 24 hours.

\subsection{Fourier Transform Infrared Spectroscopy (FTIR) Characterization.}

FTIR analysis of the extract was utilized to characterize the functional groups in it, while that of the corrosion product was utilized to check that the inhibition comes from the interaction between the metal and the extract [31]. "The FTIR spectra for crude Viscum album, Viscum album extract in $1 \mathrm{M} \mathrm{HCl}$ solution, and the corrosion products are presented in Fig. 13. The results obtained indicate that the interaction between the extract and the CS resulted in the inhibition process. FTIR of Viscum album in $1 \mathrm{M} \mathrm{HCl}$ displayed functional groups $\mathrm{O}-\mathrm{H}$, carboxylic acid $\mathrm{O}-\mathrm{H}$ stretching vibration, $\mathrm{C}=\mathrm{O}, \mathrm{C}-\mathrm{H}, \mathrm{C}-\mathrm{O}$, aromatic $\mathrm{C}-\mathrm{H}$ bending vibration and $\mathrm{NH}$ contain oxygen and nitrogen atoms and unsaturated $(\mathrm{C}=\mathrm{C})$. The oxygen and nitrogen atoms in the extract give the general features of model corrosion inhibitors". The moves in the spectra in the existence of the CS to Viscum album extract in $1 \mathrm{M} \mathrm{HCl}$ due to interaction among Viscum album extract and the CS through the functional groups' attendance in the Viscum album extract resulted in protection.

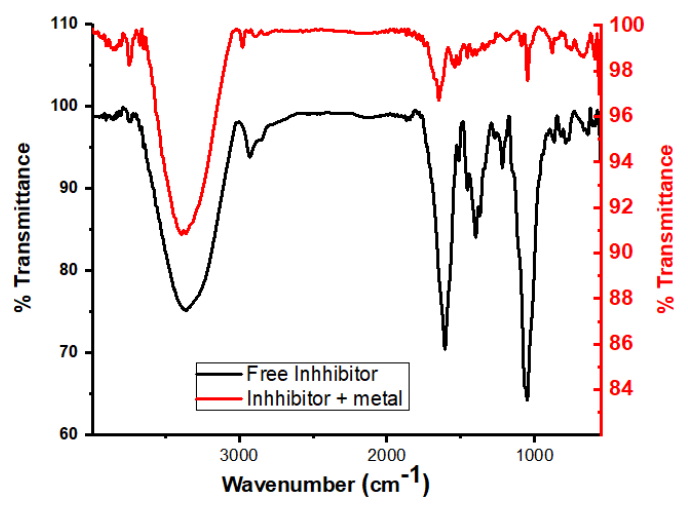

Figure 13. FTIR of Viscum album extract alone and $\mathrm{HCl}+$ Viscum album after $24 \mathrm{~h}$ immersion.

\subsection{XPS analysis.}

The formed layer of the extract on the surface of the CS metal in $1 \mathrm{M} \mathrm{HCl}$, proving the adsorption nature of the Viscum album extract. Figure 14 shows the XPS decomposition spectra for each element separately, which are found in the surface layer formed in a solution that controls the existence of the Viscum album extracted. The CS metal spectra recorded when 
dipped in a $1.0 \mathrm{M} \mathrm{HCl}$ inclosing the highest concentration of Viscum album extract (300 ppm) were for $\mathrm{Cl} 2 \mathrm{p}, \mathrm{Fe} 2 \mathrm{p}, \mathrm{O}$ 1s, N1s, and C1s. Table 8 shows the binding energies date (BE, eV) and the same assignment for every peak constituent [31]. Different peaks were observed at binding energy data of the $\mathrm{Cl} 2 \mathrm{p}, \mathrm{Fe} 2 \mathrm{p}, \mathrm{O} 1 \mathrm{~s}, \mathrm{~N} 1 \mathrm{~s}$, and $\mathrm{C} 1 \mathrm{~s}$, which were found in $1 \mathrm{M}$ hydrochloric acid and 300 ppm of Viscum album extract. Previous results obtained from XPS analysis established the adsorption of Viscum album molecules on the CS surface.

\section{Survey}

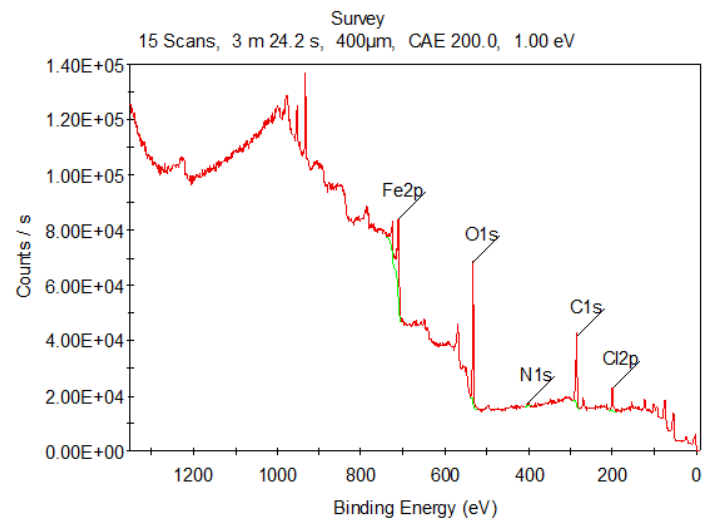

\section{O1s}

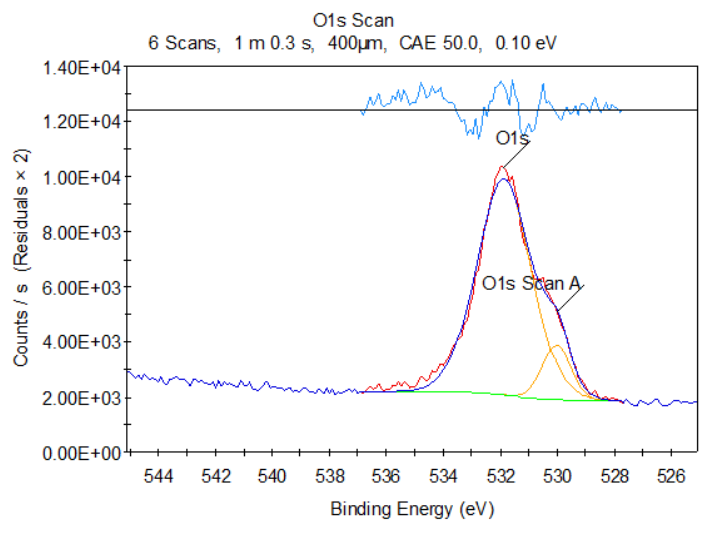

\section{C1s}

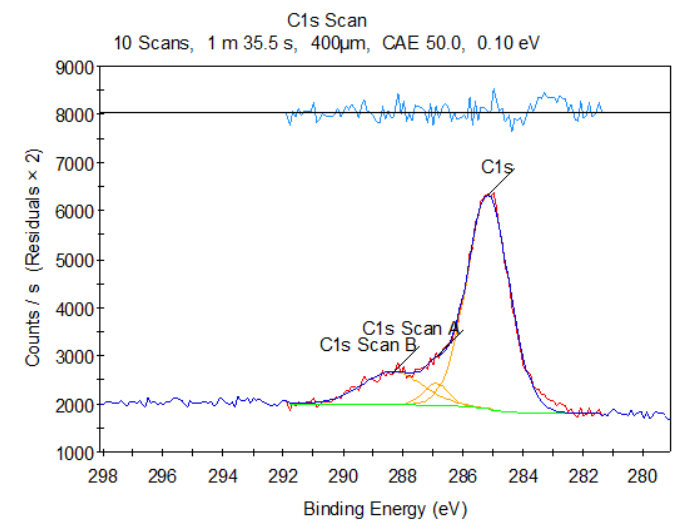

Fe2p

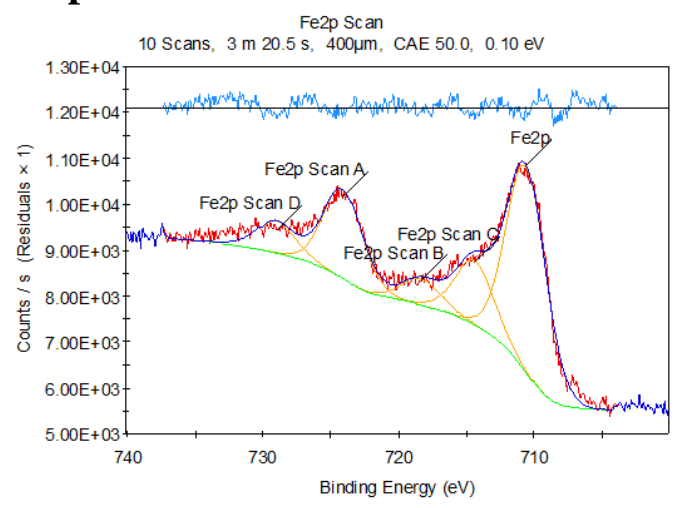

N1s

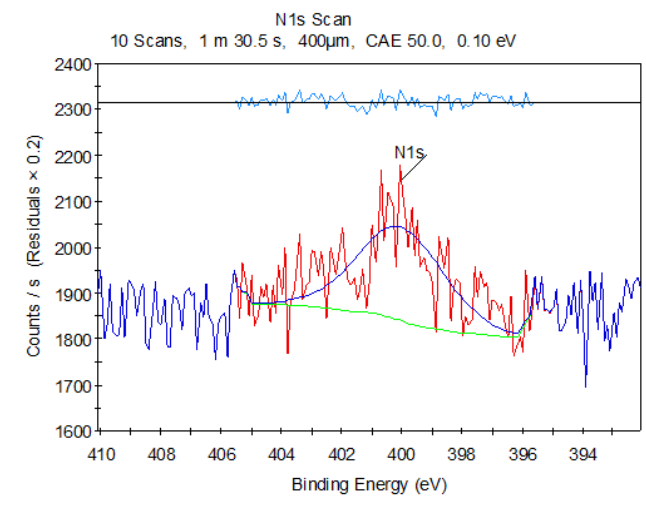

Cl2p

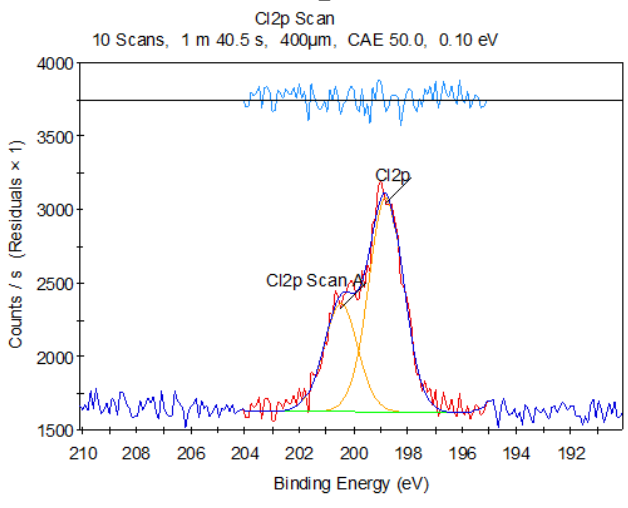

Figure 14. Photoelectric X-rays results from Survey, Fe2p, O 1s, N1s, C1s, and Cl2p for CS at 1M hydrochloric acid solutions with 300ppm from Viscum album extract.

\subsection{Mechanism of inhibition.}

The mechanism of adsorption and protection of Viscum album extract in $\mathrm{HCl}$ solution can be clarified as the chemisorption process. 
Table 8. Binding energies $(\mathrm{eV})$ for the large core lines observed for the surface of CS, which is handled by

\begin{tabular}{|c|c|c|}
\hline \multicolumn{3}{|c|}{ Viscum album extract. } \\
\hline $\begin{array}{l}\text { Core } \\
\text { element }\end{array}$ & BE, eV & Assignments \\
\hline \multirow{3}{*}{$\mathrm{C} 1 \mathrm{~s}$} & 285.17 & \multirow{3}{*}{$\begin{array}{c}\mathrm{C}-\mathrm{C}, \\
-\mathrm{C}=\mathrm{O}, \mathrm{C}-\mathrm{H}\end{array}$} \\
\hline & 286.91 & \\
\hline & 288.34 & \\
\hline \multirow{2}{*}{$\mathrm{O} 1 \mathrm{~s}$} & 531.87 & \multirow{2}{*}{$\mathrm{Fe}_{2} \mathrm{O}_{3}, \mathrm{Fe}(\mathrm{OH})_{3}$} \\
\hline & 530.03 & \\
\hline N1s & 400.03 & $\mathrm{~N}-\mathrm{Fe}$ \\
\hline \multirow{5}{*}{$\mathrm{Fe} 2 \mathrm{p}$} & 710.59 & \multirow{5}{*}{$\begin{array}{c}\mathrm{Fe}_{2} \mathrm{O}_{3} / \mathrm{Fe}_{3} \mathrm{O}_{4} / \mathrm{FeOOH} \\
\mathrm{FeCl}_{3}\end{array}$} \\
\hline & 724.07 & \\
\hline & 718.34 & \\
\hline & 714.41 & \\
\hline & 728.99 & \\
\hline $\mathrm{Cl} 2 \mathrm{p}$ & 198.8 & $\mathrm{Cl} 2 \mathrm{p} 3 / 2$ \\
\hline
\end{tabular}

The coordinate bond is formed among the Viscum album molecules and the metal surface by sharing or transferring the electrons. The corrosion inhibition of the Viscum album molecules is, in fact, due to the existence of electron donor groups ( $\mathrm{O}$ and $\mathrm{N})$ and $\pi$-electrons on an aromatic ring in its Viscum album molecules. The existence of transition metal with unoccupied d-orbital and Viscum album with chemical constituents containing $\pi$-electrons and hetero atoms with a free lone pair of electrons $(\mathrm{N}, \mathrm{O}, \mathrm{S})$ is necessary and widely aid in the adsorption process. The interactions among the vacant d-orbitals of iron atoms (an electron acceptor) and the $\pi$-electrons on the ring (an electron donor) facilitate Viscum album molecules' adsorption by chemical adsorption. The Viscum album molecules can form an insoluble complex by reacting with the Fe2+ present on the CS surface and making a barrier on the metal surface $[32,33]$.

\section{Conclusions}

The impact of Viscum album extract as a green corrosion inhibitor for the CS in aqueous environment was performed utilizing ML, PP and EIS techniques. The ML, PP, and EIS measurements support the assumption that corrosion inhibition primarily occurs through adsorption of the Viscum album molecules on the CS surface following Temkin adsorption isotherm. PP data revealed that this extract acted as a mixed kind inhibitor. The \%IE depends upon the temperature and doses of the extract. Agreement among these different independent techniques indicates the validity of the obtained results. Viscum album extract adsorbed on the CS surface and via the free electrons of oxygen or nitrogen atoms in addition to the electrons in benzene rings. The adsorbed protective film was confirmed using AFM, FTIR, and XPS techniques. This study shows that Viscum album extract has proven to be an important, environmentally friendly, and low-cost inhibitor for CS in acid medium.

\section{Funding}

This research received no external funding.

\section{Acknowledgments}

All our gratitude to the anonymous referees for their careful reading of the manuscript and valuable comments helped shape this paper to the present form. We thank all laboratory staff of corrosion chemistry from the University of Mansoura (Egypt) for their kind cooperation. 


\section{Conflicts of Interest}

The authors declare that there is no conflict of interest between them and anybody else.

\section{References}

1. Verma, C.; Quraishi, M.A.; Ebenso, E.E. Microwave and ultrasound irradiations for the synthesis of environmentally sustainable corrosion inhibitors: An overview. Sustainable Chemistry and Pharmacy 2018, 10, 134-147, https://doi.org/10.1016/j.scp.2018.11.001.

2. Shetty, D.S.; Shetty, P.; Nayak, S.H.V. The inhibition action of N-furfuryl-N'-phenyl thiourea on the corrosion of mild steel in acid media. J. Serb. Chem. Soc. 2006, 71, 1073-1082, https://doi.org/10.2298/JSC06101073S.

3. Aoun, S.B.; Messali, M. Microwave-assisted synthesis of green inhibitor for carbon steel acid corrosion. Int. J. Electrochem. Sci 2018, 13, 3757-3776, https://doi.org/10.20964/2018.04.55.

4. Popoola, L.T. Progress on pharmaceutical drugs, plant extracts and ionic liquids as corrosion inhibitors. Heliyon 2019, 5, e01143, https://doi.org/10.1016/j.heliyon.2019.e01143.

5. Haldhar, R.; Prasad, D.; Bahadur, I.; Dagdag, O.; Berisha, A. Evaluation of Gloriosa superba seeds extract as corrosion inhibition for low carbon steel in sulfuric acidic medium: A combined experimental and computational studies. J. Mol. Liq. 2021, 323, 114958, https://doi.org/10.1016/j.molliq.2020.114958.

6. Agbaffa, E.B.; Akintemi, E.O.; Uduak, E.A.; Oyeneyin, O.E. Corrosion inhibition potential of the methanolic crude extract of Mimosa pudica leaves for mild steel in $1 \mathrm{M}$ hydrochloric acid solution by weight loss method. Science Letters 2021, 15, 23-42, https://doi.org/10.24191/sl.v15i1.11791.

7. Vorobyova, V.; Skiba, M. Peach Pomace Extract as Efficient Sustainable Inhibitor for Carbon Steel Against Chloride-Induced Corrosion. Journal of Bio- and Tribo-Corrosion 2020, 7, 11, https://doi.org/10.1007/s40735-020-00450-y.

8. Mohammed, A.-R.I.; Solomon, M.M.; Haruna, K.; Umoren, S.A.; Saleh, T.A. Evaluation of the corrosion inhibition efficacy of Cola acuminata extract for low carbon steel in simulated acid pickling environment. Environmental Science and Pollution Research 2020, 27, 34270-34288, https://doi.org/10.1007/s11356-02009636-w.

9. Peñaloza, E.; Holandino, C.; Scherr, C.; Araujo, P.I.P.d.; Borges, R.M.; Urech, K.; Baumgartner, S.; Garrett, R. Comprehensive Metabolome Analysis of Fermented Aqueous Extracts of Viscum album L. by Liquid Chromatography-High Resolution Tandem Mass Spectrometry. Molecules 2020, 25, https://doi.org/10.3390/molecules25174006.

10. Urech, K.; Baumgartner, S. Chemical constituents of Viscum album L.: implications for the pharmaceutical preparation of mistletoe. Mistletoe: From mythology to evidence-based medicine 2015, 4, 11-23, https://doi.org/10.1159/000375422.

11. Khadraoui, A.; Khelifa, A.; Hamitouche, H.; Mehdaoui, R. Inhibitive effect by extract of Mentha rotundifolia leaves on the corrosion of steel in $1 \mathrm{M} \mathrm{HCl}$ solution. Res. Chem. Intermed. 2014, 40, 961-972, https://doi.org/10.1007/s11164-012-1014-y.

12. Fouda, A.S.; Abousalem, A.S.; El-Ewady, G.Y. Mitigation of corrosion of carbon steel in acidic solutions using an aqueous extract of Tilia cordata as green corrosion inhibitor. International Journal of Industrial Chemistry 2017, 8, 61-73, https://doi.org/10.1007/s40090-016-0102-z.

13. Okafor, P.C.; Ikpi, M.E.; Uwah, I.E., Ebenso, E.E.; Ekpe, U.J.; Umoren, S.A. Inhibitory action of Phyllanthus amarus extracts on the corrosion of mild steel in acidic media. Corros. Sci. 2008, 50, 2310-2317, https://doi.org/10.1016/j.corsci.2008.05.009.

14. Raghavendra, N.; Hublikar, L.V.; Patil, S.M.; Ganiger, P.J.; Bhinge, A.S. Efficacy of sapota leaf extract against aluminium corrosion in a $3 \mathrm{M}$ sodium hydroxide hostile fluid atmosphere: a green and sustainable approach. Bull. Mater. Sci. 2019, 42, 226, https://doi.org/10.1007/s12034-019-1922-1.

15. Fouda, A.S.; Abd El-Maksoud, S.A.; El-Hossiany, A.; Ibrahim, A. Corrosion protection of stainless steel 201 in acidic media using novel hydrazine derivatives as corrosion inhibitors. Int. J. Electrochem. Sci 2019, 14, 2187-2207, https://doi.org/10.20964/2019.03.15.

16. Boumhara, K.; Harhar, H.; Tabyaoui, M.; Bellaouchou, A.; Guenbour, A.; Zarrouk, A. Corrosion Inhibition of Mild Steel in 0.5 M H2SO4 Solution by Artemisia herba-alba Oil. Journal of Bio- and Tribo-Corrosion 2018, 5, 8, https://doi.org/10.1007/s40735-018-0202-8. 
17. Fouda, A.S.; Rashwan, S.; Kamel, M.M.; Arman, N.M. Adsorption, and inhibition behavior of avicennia marina for $\mathrm{Zn}$ metal in hydrochloric acid solution. Int. J. Electrochem. Sci 2017, 12, 11789-11804, https://doi.org/10.20964/2017.12.95.

18. Fouda, A.; Azeem, M.A.; Mohamed, S.; El-Desouky, A. Corrosion inhibition and adsorption behavior of nerium oleander extract on carbon steel in hydrochloric acid solution. International Journal of Electrochemical Science 2019, 14, 3932-3948, https://doi.org/10.20964/2019.04.44.

19. Fouda, A.S.; Rashwan, S.; El-Hossiany, A.; El-Morsy, F. E. Corrosion Inhibition of Zinc in Hydrochloric Acid Solution using some organic compounds as Eco-friendly Inhibitors. JCBPS. 2019, 9(1), 001-024, https://doi.org/10.24214/jcbps.A.9.1.00124.

20. Fouda, A.S.; Abd El-Maksoud, S.A.; Belal, A.A.M.; El-Hossiany, A.; Ibrahim, A. Effectiveness of Some Organic Compounds as Corrosion Inhibitors for Stainless Steel 201 in $1 \mathrm{M} \mathrm{HCl}$ : Experimental and Theoretical Studies. Int. J. Electrochem. Sci 2018, 13, 9826-9846, https://doi.org/10.20964/2018.10.36.

21. Ibrahim, M.B.; Sulaiman, Z.; Usman, B.; Ibrahim, M.A. Effect of Henna Leaves on the Corrosion Inhibitor of Tin in Acidic and Alkaline Media. World 2019, 4, 45-51, https://doi.org/10.11648/j.wjac.20190404.11.

22. Wasim, M.; Shoaib, S.; Mubarak, N.M.; Inamuddin; Asiri, A.M. Factors influencing corrosion of metal pipes in soils. Environ. Chem. Lett. 2018, 16, 861-879, https://doi.org/10.1007/s10311-018-0731-x.

23. Baymou, Y.; Bidi, H.; Ebn Touhami, M.; Allam, M.; Rkayae, M.; Belakhmima, R.A. Corrosion Protection for Cast Iron in Sulfamic Acid Solutions and Studies of the Cooperative Effect Between Cationic Surfactant and Acid Counterions. Journal of Bio- and Tribo-Corrosion 2018, 4, 11, https://doi.org/10.1007/s40735-0180127-2.

24. Fouda, A.S.; Abd El-Maksoud, S.A.; El-Hossiany, A.; Ibrahim, A. Evolution of the corrosion-inhibiting efficacy of novel hydrazine derivatives against corrosion of stainless steel 201 in acidic medium. Int. J. Electrochem. Sci 2019, 14, 6045-6064, https://doi.org/10.20964/2019.07.65.

25. Fouda, A.S.; Killa, H.M.; Farouk, A.; Salem, A.M. Calicotome Extract as a Friendly Corrosion Inhibitor for Carbon Steel in Polluted $\mathrm{NaCl}$ Solution: Chemical and Electrochemical Studies. Egyptian Journal of Chemistry 2019, 62, 1879-1894, https://doi.org/10.21608/EJCHEM.2019.7656.1649.

26. Fouda, A.S.; Eissa, M.; El-Hossiany, A. Ciprofloxacin as eco-friendly corrosion inhibitor for carbon steel in hydrochloric acid solution. Int. J. Electrochem. Sci 2018, 13, 11096-11112, https://doi.org/10.20964/2018.11.86.

27. Fouda, A.S.; Abdel Haleem, E. Berry Leaves Extract as Green Effective Corrosion Inhibitor for Cu in Nitric Acid Solutions. Surface Engineering and Applied Electrochemistry 2018, 54, 498-507, https://doi.org/10.3103/S1068375518050034.

28. Hsissou, R.; Abbout, S.; Berisha, A.; Berradi, M.; Assouag, M.; Hajjaji, N.; Elharfi, A. Experimental, DFT and molecular dynamics simulation on the inhibition performance of the DGDCBA epoxy polymer against the corrosion of the E24 carbon steel in $1.0 \mathrm{M} \mathrm{HCl}$ solution. J. Mol. Struct. 2019, 1182, 340-351, https://doi.org/10.1016/j.molstruc.2018.12.030.

29. Fouda, A.S.; El-Ewady, G.; Ali, A.H. Modazar as promising corrosion inhibitor of carbon steel in hydrochloric acid solution. Green Chemistry Letters and Reviews 2017, 10, 88-100, https://doi.org/10.1080/17518253.2017.1299228.

30. Habibiyan, A.; Ramezanzadeh, B.; Mahdavian, M.; Kasaeian, M. Facile size and chemistry-controlled synthesis of mussel-inspired biopolymers based on Polydopamine Nanospheres: Application as eco-friendly corrosion inhibitors for mild steel against aqueous acidic solution. J. Mol. Liq. 2020, 298, 111974, https://doi.org/10.1016/j.molliq.2019.111974.

31. Motawea, M.M.; El-Hossiany, A.; Fouda, A.S. Corrosion control of copper in nitric acid solution using chenopodium extract. Int. J. Electrochem. Sci 2019, 14, 1372-1387, https://doi.org/10.20964/2019.02.29.

32. Soltani, N.; Tavakkoli, N.; Attaran, A.; Karimi, B.; Khayatkashani, M. Inhibitory effect of Pistacia khinjuk aerial part extract for carbon steel corrosion in sulfuric acid and hydrochloric acid solutions. Chemical Papers 2020, 74, 1799-1815, https://doi.org/10.1007/s11696-019-01026-y.

33. Zhang, S.; Hou, L.; Du, H.; Wei, H.; Liu, B.; Wei, Y. A study on the interaction between chloride ions and CO2 towards carbon steel corrosion. Corros. Sci. 2020, 167, 108531, https://doi.org/10.1016/j.corsci.2020.108531. 